ISSN: 2594-4827

\title{
TERREIRO PAI XANGÔ DAS CACHOEIRAS: PRÁTICAS DE EDUCAÇÃo PROFISSIONAL E TECNOLÓGICA (EPT)
}

\author{
Cláudio Rodrigues dos Santos ${ }^{1}$ \\ Francisco Vanderlei Ferreira da Costa ${ }^{2}$
}

\section{RESUMO}

Este artigo resulta de uma pesquisa documental em um Terreiro de Candomblé. Teve o objetivo de analisar o processo de ensino e aprendizagem realizado na Escola de Arte Escultural do Terreiro para compreender as interfaces dessas práticas com a Educação Profissional e Tecnológica tendo o trabalho como princípio educativo. Pesquisou-se a história do Terreiro e o trabalho para a produção do artesanato. Essa perspectiva de trabalho permeia a formação e profissionalização dos/as filhos/as de santo e da comunidade do entorno. Foram analisados documentos institucionais, livros, artigos e filme, que abordam a produção do artesanato na casa religiosa. Nesses documentos estão registrados aspectos tanto do modo de vida quanto da procura por colocação trabalhista das pessoas que frequentam o Terreiro.

Palavras-chave: Terreiro de Candomblé; Povos e Comunidades Tradicionais; Educação Profissional e Tecnológica.

\section{'PAI XANGÔ DAS CACHOEIRAS' TERREIRO: PRACTICES OF TECHNICAL AND VOCATIONAL EDUCATION (TVE)}

\begin{abstract}
This article is the result of a documentary research in a Candomblé "Terreiro". It aimed to analyze the teaching and learning process carried out at the Terreiro's School of Sculptural Artto understand the interfaces of these practices with Technical and Vocational Education having work as an educational principle. The Terreiro'shistory and the work in the production of handicrafts were researched. This work perspective permeates the training and professionalization of the "filhos de santo" and the surrounding community. We analyzed institutional documents, books, articles and film, which discuss the production of handicrafts in the religious house. These documents record aspects of both the way of life and the demand for job placement by people who attend the Terreiro.
\end{abstract}

\footnotetext{
${ }^{1}$ Licenciado em pedagogia pela Universidade do Estado da Bahia (UNEB). Acadêmico do curso de mestrado profissional em Educação Profissional e Tecnológica - ProfEPT no Instituto Federal de Educação, Ciência e Tecnologia da Bahia. Coordenador Executivo da Coordenação de Políticas para Povos e Comunidades Tradicionais (CPPCT/SEPROMI).negrodagua@outlook.com

${ }^{2}$ Professor do Instituto Federal da Bahia - IFBA. Leciona no Mestrado Profissional em Educação Profissional e Tecnológica. francisco@ifba.edu.br
} 
Keywords: Candomblé "terreiro"; Traditional peoples and communities; Technical and vocational education.

\section{INTRODUÇÃO}

Este artigo resulta de uma pesquisa que teve objetivo de analisar o processo de ensino e aprendizagem realizado na Escola de Arte Escultural do Terreiro Pai Xangô das Cachoeiras, localizado no Município da Barra, Território de Identidade Velho Chico, Bahia. Buscamos compreender as interfaces das práticas de ensino e aprendizagem realizadas pelo Terreiro com a Educação Profissional e Tecnológica (EPT) tendo em vista o entendimento de trabalho como princípio educativo presentes nos estudos de Acácia Zeneida Kuenzer (1989) e de Demerval Saviani (2007).

A escolha metodológica da pesquisa foi definida considerando o momento pandêmico global de importância internacional estabelecido pela Organização Mundial de Saúde (OMS) em função da pandemia do Coronavírus (Covid-19) que tem obrigado a todas as pessoas a seguirem os mais rígidos protocolos sanitários das autoridades e cientistas da área de saúde: isolamento social, uso de máscaras, fechamento de espaços coletivos para se evitar aglomeração de pessoas, dentre outros. Por isso, optamos pela abordagem metodológica da pesquisa documental, de modo que o contato pessoal se limitasse às lideranças religiosas para acesso ao espaço da casa religiosa e análise dos principais documentos institucionais ou publicados referente ao terreiro. Também foram utilizadas outras fontes para a coleta dos dados: três livros, um artigo e um filme que abordam a história do espaço religioso, suas práticas e ritos sagrados, bem como os processos de ensino e aprendizagem realizados com madeira e barro para criação de artesanatos na Escola de Arte Escultural vinculada ao Terreiro de Candomblé. Todas as fontes citadas estão com publicação datada entre os anos de 1996 a 2019.

Em relação à educação nos Terreiros de Candomblé, utilizamos os estudos realizados por Amurabi Oliveira e Kleverton Arthur de Almirante (2014), e Renata Silva da Costa (2015). Já sobre Educação Profissional e Tecnológica (EPT), dialogamos com algumas abordagens de Dante Henrique Moura, Sandra Regina de Oliveira Garcia e Marise Nogueira Ramos (2007), Demerval Saviani (1994, 2007), Acácia Zeneida Kuenzer (1989) e Sandra Soares Della Fonte (2018).

A partir dos estudos e das análises realizados foi possível identificar elementos 
caraterísticos da Educação Profissional e Tecnológica (EPT), conforme entendimento de seus estudiosos e formuladores, no processo de ensino e aprendizagem, do trabalho como princípio educativo e, de modo geral, nos arranjos organizativos, produtivos, sociais, culturais e religiosos do Terreiro de Candomblé. A partir da identificação dos elementos das práticas do Terreiro, foi possível articular a ideia de Politecnia defendida pelo professor Saviani (2007) ao trabalho desenvolvido pelo Terreiro. Trabalho esse que, segundo as lideranças religiosas da casa, tem o objetivo principal de incluir crianças, jovens, mulheres e homens que muitas vezes são deixados à margem da sociedade, seja no que tange à escolaridade, seja na perspectiva da profissionalização para o trabalho.

O texto está estruturado em três momentos. No primeiro são feitas algumas considerações sobre: a) Povos e Comunidades Tradicionais (PCTs), sua caracterização em conformidade com o normativo legal vigente, o Decreto 6.040 de 2007 (Brasil, 2007), que institui a Política Nacional de Desenvolvimento Sustentável dos Povos e Comunidades Tradicionais no país; b) sobre invisibilidade desses Povos e Comunidades Tradicionais (PCTs), particularmente, no campo dos estudos e pesquisas sociais e acadêmicas, com ênfase especial para os Povos e Comunidades Tradicionais de Matriz Africana tendo em vista dados produzidos pela Secretaria de Políticas de Promoção da Igualdade Racial, entre os anos de 2013 e 2015.

No segundo momento, caracterizamos os espaços do Terreiro Pai Xangô das Cachoeiras e do papel de destaque que assume o líder religioso, para delinear as práticas e os processos de ensino e aprendizagem aí desenvolvidos. Focamos no trabalho com o barro e madeira por serem os principais elementos utilizados para as atividades relacionadas à produção do artesanato e, por consequência da formação do estudante/artesão. E no terceiro momento, é apresentado o resultado das análises dos registros encontrados nas fontes pesquisadas que qualificam, destacam e caracterizam os materiais, os conteúdos, os procedimentos e o público envolvido no processo de ensino e de aprendizagem de produção do artesanato no Terreiro e na Escola de Arte Escultural e suas interfaces com a Educação Profissional e Tecnológica.

\section{INVISIBILIDADE DOS POVOS E COMUNIDADES TRADICIONAIS}

A escolha de um Terreiro de Candomblé demarca a perspectiva epistemológica de 
racialização desse trabalho. Essa opção de estudo é um posicionamento político de reconhecimento e reafirmação da luta da População Negra e dos Povos e Comunidades Tradicionais perante o Racismo Estrutural. Nesse sentido, iniciamos trazendo à tona a problemática da exclusão e invisibilidade dos Povos e Comunidades Tradicionais como sendo uma das marcas legadas a esses grupos pelo Racismo Estrutural.

Não é novidade que o processo de exclusão de grupos minorizados também se aplica para tornar invisíveis os grupos étnicos-raciais denominados Povos e Comunidades Tradicionais $^{3}$. Como se sabe, essa nomeação, Povos e Comunidades Tradicionais, perante o Estado brasileiro é nova e foi efetivamente incorporada na legislação no ano de 2007, quando se cria uma política nacional, por meio do decreto 6040/07.

Cabe frisar que esse decreto, assim como as Leis $n^{\circ} 10.639 / 2006, n^{\circ} 11.645 / 2008, n^{\circ}$ 12.288/2010 (Estatuto da Igualdade Racial), n 13.005/2014 (Plano Nacional de EducaçãoMetas 12.5, 12.9, 12.11), e o Decreto $\mathrm{n}^{\circ} 4.887 / 2003$, estende a grupos não mencionados na Constituição de 1988, direitos e garantias legais. No que pese esse reconhecimento, via legislação, ser um grande avanço conquistado pelos movimentos realizados pelos Povos e Comunidades Tradicionais diante do Estado, muitos direitos ainda são negados.

No que pese estar vigente uma Política Nacional específica para esses grupos, conforme Decreto 6.040/2007 (Brasil, 2007), e demais normativos já citados, as políticas públicas executadas pelo Estado são muito restritas e não atendem as demandas básicas desses grupos por água para consumo humano, energia elétrica, estrada, moradia, segurança alimentar e nutricional, acesso à justiça, reconhecimento do seu modo de vida, desenvolvimento econômico sustentável, saúde e educação, etc. E é nesse contexto de exclusão que também se opera a invisibilidade dos Povos e Comunidades Tradicionais.

Este estudo focou em um dos segmentos do grupo dos PCTs, o segmento de Terreiro de Candomblé. Um segmento que também não foge à regra do processo de exclusão e invisibilidade. Sabe-se que o Racismo Estrutural também fundamenta esse processo de exclusão e invisibilidade que afeta todos os Povos e Comunidades Tradicionais, e no caso específico do segmento de Terreiro de Candomblé, afeta, principalmente, através das práticas,

\footnotetext{
${ }^{3}$ Decreto Federal 6.040 de 07 de fevereiro de 2007, Art. $3^{\circ}$ Para os fins deste Decreto e do seu Anexo compreende-se por: I - Povos e Comunidades Tradicionais: grupos culturalmentediferenciados e que se reconhecem como tais, que possuem formas próprias de organização social, que ocupam e usam territórios e recursos naturais como condição para sua reprodução cultural, social, religiosa, ancestral e econômica, utilizando conhecimentos, inovações e práticas gerados e transmitidos pela tradição.
} 
ISSN: 2594-4827

mecanismos e manifestações que caracterizam o racismo religioso, comumente conhecido como intolerância religiosa.

Esse estado de exclusão e invisibilidade, como se observa na sociedade brasileira, também determina vários campos dos estudos e pesquisas sociais e acadêmicas sobre o complexo modo de vida dos Terreiros de Candomblé. Dessa maneira, as diversas práticas que transcendem a religiosidade, nesses espaços religiosos, que se conformam em muitas outras nos campos da produção tecnológica, das práticas profissionais, das artes, dos artesanatos e da educação, etc., são igualmente ignoradas por conta dessa invisibilidade. Quando consideramos somente os processos relacionados ao ensino e aprendizagem que caracterizam a educação presente nos Terreiros de Candomblé, estudos como o realizado por Amurabi Oliveira e Kleverton Arthur de Almirante (2014, p. 4), são bastante reveladores desse quadro de exclusão.

Cabe pontuar que a produção acadêmica acerca da relação entre o Candomblé e a educação é recente e tem partido em sua maioria das perspectivas multiculturais e interculturais do ensino (CANDAU; LEITE, 2012), muitas vezes lançando mão de conceitos teóricos e propostas metodológicas da Antropologia. Nos registros feitos no banco de teses da Coordenação de Aperfeiçoamento de Pessoal de Nível Superior (CAPES), o número de pesquisas realizadas em todo o Brasil que relacionaram precisamente as temáticas de "Candomblé, educação e escola" foi 15 em nível de Mestrado e 4 em nível de Doutorado.

O quadro trazido pelos autores é extremamente relevante e evidencia o quão invisibilizados são os Terreiros de Candomblé quando se trata da produção realizada pelos centros acadêmicos. As academias ignoram, em grande medida, as epistemologias e os fazeres desse segmento. Tratando desse mesmo processo de exclusão e invisibilidade, um outro importante estudo foi realizado pela Secretaria de Políticas de Promoção da Igualdade Racial (SEPPIR), órgão ligado à Presidência da República até o ano de 2019, que apresentou à sociedade brasileira o Plano Nacional de Desenvolvimento Sustentável do Povos e Comunidades Tradicionais de Matriz Africana para o triênio 2013 - 2015, no qual destacava que:

A invisibilidade dos povos e comunidades tradicionais de matriz africana se reflete na ausência de levantamentos e dados oficiais sobre essa parcela da população brasileira. Atualmente são conhecidos sete levantamentos realizados por instituições públicas, privadas e universidades que buscaram cadastrar, inventariar ou mapear territórios tradicionais de matriz africana. Os dados desses levantamentos, ainda parciais em relação ao universo Brasil, são relativos a um total de 7.582 casas de tradição de matriz africana 
ISSN: 2594-4827

(SEPPIR, 2013, p.18).

Os estudos mencionados, realizados por Oliveira e Almirante (2014) e pela SEPPIR, mostram o quanto se faz necessário demarcar o lugar dos PCTs, como um espaço de conhecimento, saberes, fazeres práticos, cultura, etc., que na maior parte da história são taxados como desinteressantes e desnecessários ao processo produtivo de acumulação do capital.

Essa reflexão sobre a exclusão e a invisibilidade do modo de vida dos PCTs nos possibilita problematizar o porquê que práticas produtivas culturais como as desenvolvidas pelos PCTs ainda não estão ao alcance da lente da ciência e até mesmo do capital comercial ganancioso que a tudo quer se apropriar. Será mesmo que não há potencialidades nos espaços de manifestação da vida dos Povos e Comunidades Tradicionais para o desenvolvimento de forças produtivas a partir, por exemplo, de uma forma de Educação Profissional e Tecnológica que prepare mão de obra profissional para o mundo do trabalho? Ou será porque no modo de vida desses grupos se encerra uma perspectiva de produção da vida que aponte para outra forma civilizatória onde a educação, o trabalho, a tecnologia, o conhecimento, a arte, a ancestralidade, etc., tenham uma função diferente da função mercadológico-comercial vigente na sociedade capitalista?

Uma hipótese bastante exequível para a exclusão e a invisibilidade dos Terreiros de Candomblé e dos PCTs, de modo geral, está na possibilidade de que esses grupos possam revelar e informar, contraditoriamente, outra potencialidade civilizatória e humanizadora, a qual está presente no modo de vida desses grupos sociais, entretanto está sendo vista como desnecessária ao capital nesse período da história.

\section{O TERREIRO DE CANDOMBLÉ PAI XANGÔ DAS CACHOEIRAS E O BABALORIXÁ MESTRE ARTESÃO}

Apesar dos mecanismos de exclusão e invisibilidade aos quais são submetidos os Povos e as Comunidades Tradicionais, muitas experiências nas áreas das tecnologias, da cultura, do trabalho, da educação, das artes, da vida coletiva em comunidade, entre outros, são desenvolvidas pelo conjunto desses PCTs pelo mundo a fora. São várias as alternativas, concretizadas em ações, que esses grupos desenvolveram e desenvolvem para enfrentar e superar as barreiras impostas para seu isolamento.

A experiência do Terreiro de Candomblé Pai Xangô das Cachoeiras, através da Escola 
de Arte Escultural para a produção do artesanato se constitui como uma dessas experiências, que se revela potencialmente produtora de determinada existência, como forma de resistência e manutenção do seu modo de vida. E essa experiência passa por uma forma de organização do trabalho no interior desse espaço que será foco neste momento do texto.

Ao olhar detidamente a realidade do Terreiro Pai Xangô das Cachoeiras, foi possível perceber o desenvolvimento e organização do trabalho coletivo nessa casa religiosa, onde conhecimentos tecnológicos são transmitidos e ensinados para permitir que o conjunto de cidadãos e cidadãs, adolescentes, jovens e adultos, partilhem do patrimônio cultural material e imaterial produzido coletivamente. Foi possível também enxergar uma experiência educativa profissionalizante que situa a Ciência, a Tecnologia, o Trabalho e a Cultura como dimensões formativas indissociáveis do modo de vida coletivo. Enfatizamos o caráter coletivo e comunitário desse espaço religioso como uma das características marcantes que pudemos observar durante a realização desse estudo.

O patrimônio cultural que se conforma no modo de vida do Terreiro, pode ser melhor compreendido conforme o entendimento expresso na tradição de origem marxista que, nas palavras de Sandra Soares Della Fonte (2018, p. 6), define o patrimônio cultural produzido pela humanidade como sendo "o vasto mundo de "coisas" materiais e simbólicas que resultam do trabalho e que antes não existiam na natureza: ferramentas, instrumentos, técnicas, artefatos tecnológicos, crenças, comportamentos, conhecimentos, valores, habilidades etc". Essa definição de patrimônio cultural como sendo o 'vasto mundo das coisas' resultante do trabalho para poder existir na natureza e na sociedade caracteriza muito bem a forma como o trabalho se apresenta no Terreiro de Candomblé Pai Xangô das Cachoeiras. Para bem exemplificar o exposto acima, enfatizamos a seguir o papel da liderança religiosa e a produção do artesanato como principal atividade realizada na Escola de Arte Escultural. Produção essa que materializa não só o patrimônio cultural material e imaterial do Terreiro, mas também dá forma aos elementos característicos de uma Educação Tecnológica e Profissional que se realiza em suas dependências. Essa exemplificação é realizada a partir de apresentação de narrativas e registros objetivos da casa religiosa, do Babalorixá, da produção artesanal e do próprio espaço escolar.

O Terreiro de Candomblé Pai Xangô das Cachoeiras fica localizado no bairro Santa Clara, na Cidade da Barra, Território de Identidade Velho Chico, Estado da Bahia. De acordo com o Diploma de registro emitido pela Federação de Umbanda e Candomblé dos Cultos 
Afro-Brasileiro do município de Feira de Santana, Bahia, a criação desse espaço está datada de 8 de janeiro de 1988. Segundo esse diploma, o Terreiro Pai Xangô das Cachoeiras foi fundado há 32 anos. Atualmente convivem na casa religiosa aproximadamente 40 filhos e filhas de santo.

Figura 1: Terreiro Pai Xangô das Cachoeiras

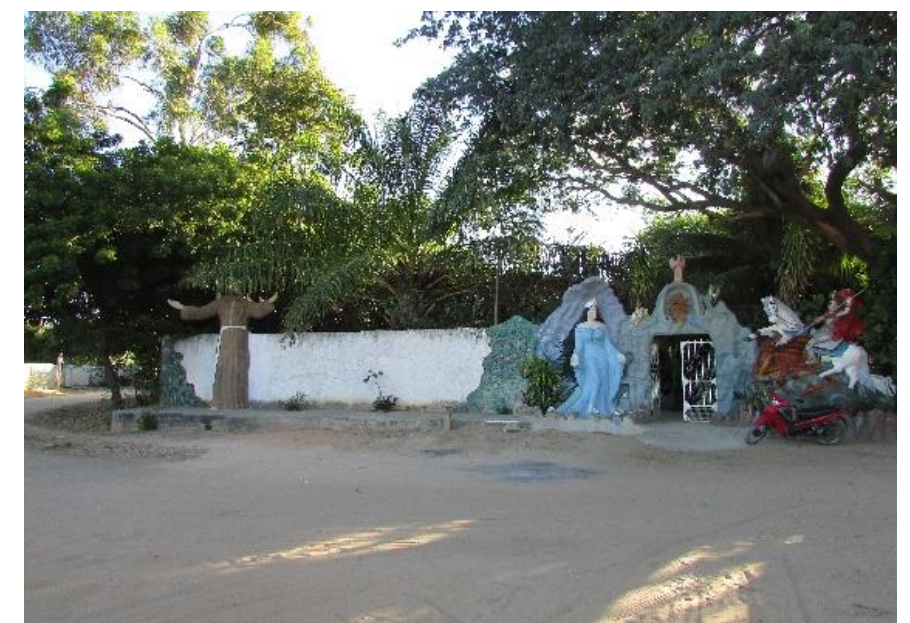

Fonte: Arquivo pessoal - Registro realizado em visita à comunidade.

O templo tem como principal autoridade religiosa o seu fundador José Geraldo da Silva. O Babalorixá ${ }^{4}$ José Geraldo, também conhecido como Gerrar $^{5}$, tem uma biografia marcada pela notoriedade alcançada como Educador e Artesão. A comprovação está em seu trabalho desenvolvido com o barro e a madeira. A produção de artesanato, cujos fundamentos estão no sincretismo religioso, ganha forma nas esculturas de barro ou de madeira que trazem de um lado a representação de corpo inteiro dos Santos da Igreja Católica e de outro dos Orixás do Candomblé numa mesma peça. No que pese utilizarmos como exemplo ilustrativo apenas o artesanato de caráter religioso, o Terreiro também produz outros tipos de peças como panelas, jarros, potes, entre outros, igualmente comerciáveis nos mercados local, estadual e nacional.

\footnotetext{
${ }^{4}$ Dicionário Online de Português: Pai dos Santos nos candomblés, xangôs e em alguns centros de umbanda, chefe espiritual e administrador da casa, responsável pelo culto aos orixás; candomblezeiro.

${ }^{5}$ Registra-se que em diversos documentos o nome de Artesão de José Geraldo aparece escrito de duas formasGerar e Gerard. Utilizamos no texto e forma Gerrar como uma tentativa de colocar na escrita a pronúncia ouvida.
} 


\section{Figura 2: José Geraldo (Gerrar), Babalorixá}

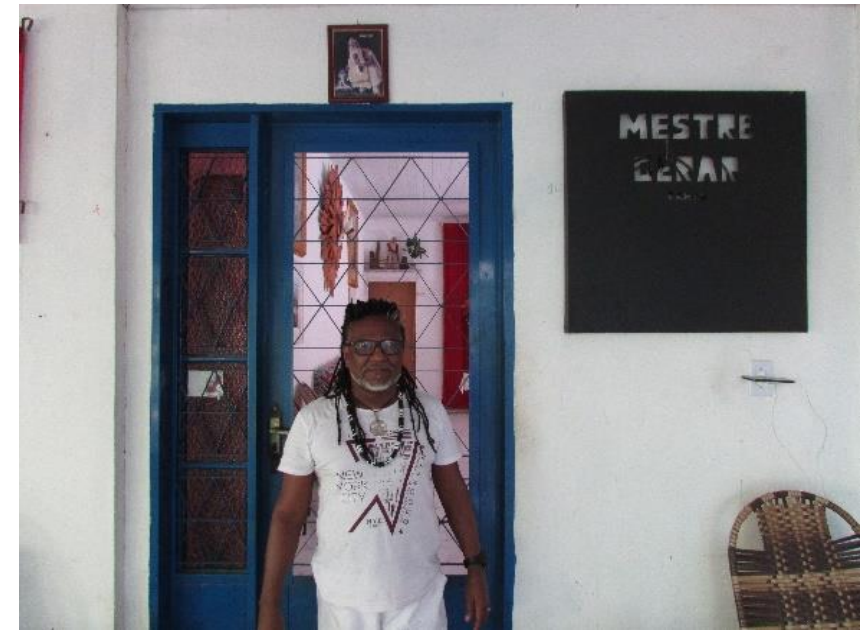

Fonte: Arquivo pessoal - Registro realizado em visita à comunidade.

Esse trabalho do Babalorixá é reconhecido em várias regiões do Brasil e também em outras partes do mundo. E foi iniciado debaixo de árvores no próprio quintal do Terreiro, segundo relatos do Babalorixá. Só no ano de 2003, passou a ser realizado na Escola de Arte Escultural quando esta foi construída.

\section{Figura 3: José Geraldo (Gerrar), Babalorixá e Mestre Artesão - trabalho com barro (foto 03).}

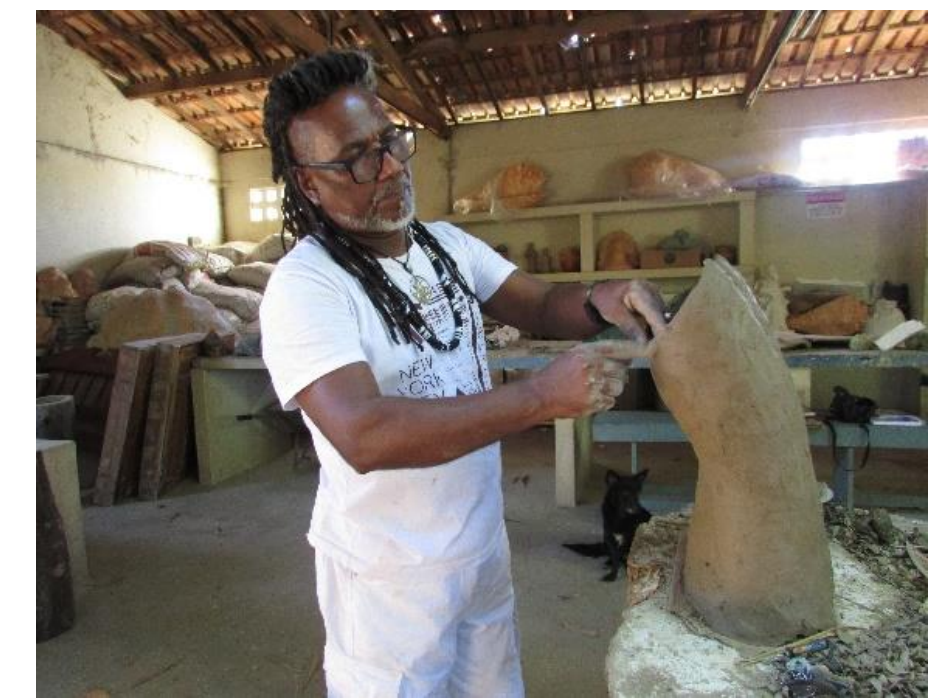

Fonte: Arquivo pessoal - Registro realizado em visita à comunidade.

Do ponto de vista da história da Educação Profissional e Tecnológica, pode se observar que o espaço dessa Escola de Arte Escultural se reveste de enorme simbologia quando analisamos a história da Educação Tecnológica e Profissional no Brasil, não só pelo 
ISSN: 2594-4827

aspecto formal/arquitetônico, mas principalmente pelas práticas de transmissão dos ofícios e ensino das artes para a produção de artesanatos. Há bastante similaridade entre o ambiente da Escola de Arte Escultural e todas as práticas que são realizadas nela com aquelas atividades que eram realizadas nas corporações de ofício que existiam espalhadas pelo Brasil durante os primeiros séculos de sua colonização. Adilso de Campos Garcia et al. (2018, p. 4) faz uma descrição detalhada desse contexto com o qual faço a relação da Escola do Terreiro. Ele narra o contexto de Brasil colonial, onde predominava a plantação da cana de açúcar, e tem-se os registros iniciais da EPT, mostrando:

A existência de pequenas oficinas de manutenção do engenho-de-açúcar, onde eram transmitidos apenas conhecimentos práticos e específicos para aquela incipiente realidade tecnológica. No entanto, pode-se afirmar que "na fase pré-colonial já viviam no Brasil artífices, mecânicos e tecelões. Dava-se curso a variadas atividades, como a feitura de utensílios agrícolas, mobiliário, iluminação, habitação e vestiário. Oleiros, ferreiros, carpinteiros, sapateiros trabalhavam para a comunidade" (GARCIA et al. 2018, p. 4).

Não se trata de mera semelhança e simbologia o fato de que as características trazidas pelo autor sobre como a EPT aparece nesse período da história do Brasil, que marca também seu nascedouro. Essa semelhança informa como a Escola de Arte Escultural do Terreiro também conserva formas identitárias comparáveis às descritas sobre os primeiros mestres e ofícios. Guardadas às devidas proporções, é possível perceber, no espaço aqui estudado, uma relação muito funcional, mantida pela comunidade frequentadora do espaço, a partir de suas reivindicações.

Feita a observação sobre os primórdios da EPT e as semelhanças com as atividades realizadas na Escola de Arte Escultural, voltamos a tratar do papel do Babalorixá na consolidação do trabalho de produção do artesanato e da função que esse trabalho assume na formação tecnológica e profissional dentro do Terreiro. Assim sendo, um dos primeiros registros encontrados sobre o trabalho do Babalorixá José Geraldo, foi publicado no ano de 2010, por Flávia Martins. A autora descreve o Babalorixá e seu trabalho da seguinte maneira:

[...] ele dá início a uma firme tradição de santeiros de Barra, cidade situada a $800 \mathrm{~km}$ de Salvador. Do ponto de vista da arte, suas iniciativas encontram um solo propício na prática funcional e na experiência refinada da atividade artesanal em barro, desenvolvida a partir da década de 90, pelo Instituto Mauá. [...] O artista não trabalha apenas com barro e madeira, mas também com pedra, corda, chifre, concreto e papel machê. Faz diferentes objetos, mas sua preferência vai para os santos católicos e para os orixás, entre os quais estabelece nítida diferença. Entende o sincretismo como uma defesa 
dos negros diante dos senhores brancos: a necessidade de cultuar seus orixás tomando os brancos como fachada (MARTINS, 2010, p. 66 e 74).

Nessa passagem apresentada por Martins (2010), fica notória a importância que tem o maior líder religioso do Terreiro ao mesmo tempo em que mostra como sua condição religiosa avança para outra dimensão cujo foco passa a ser as práticas com o artesanato. A ênfase dada à figura do líder religioso faz-se importante tão somente para compreendermos o que está sendo apresentado ao longo do texto, que são os processos de ensino e aprendizagem, e não uma supervalorização personalista de uma figura que assume um lugar de destaque na hierarquia do Terreiro. O foco é o oposto, é o processo coletivo que em muitos momentos tem como principal protagonista o trabalho realizado pelo Babalorixá junto aos aprendizes do Terreiro. O foco é o processo de aprendizagem e domínio das práticas do ofício de artesão, a aprendizagem no coletivo, na relação com os outros mestres, como é o caso do Ogan Elson Alves dos Santos, que também tem função importante na administração do Terreiro.

Para uma melhor compreensão do ambiente onde as práticas do ofício do artesanato ocorrem e para poderem ser identificados os elementos característicos desse processo de educação desenvolvido e vivenciado no ambiente da casa religiosa, Renata da Silva Costa (2015, p.8), citando Lépine (2000, p. 139-140), apresenta uma ótima colaboração e remete ao sentido do princípio educativo do trabalho para o Terreiro. Diz a autora: "um terreiro de Candomblé tem sua gente, seu pedaço de terra, suas técnicas tradicionais de trabalho, seu sistema de distribuição e de consumo de bens, sua organização social, bem como seu mundo de representações". Essa descrição do ambiente do terreiro, realizada por Costa (2015) exemplifica o sentido que o trabalho assume para o Terreiro. Isso possibilita a compreensão de que o trabalho é o princípio que estabelece a relação dialética Terreiro e educação, relação essa mediada pelo trabalho com o barro e a madeira para a produção do artesanato. $\mathrm{O}$ trabalho aparece como uma relação, uma totalidade ontológica. Uma totalidade social que orienta a produção e reprodução da vida em sociedade.

Esse entendimento de trabalho como uma relação dialética entre o saber prático e o saber intelectual é defendido pela professora Acácia Zeneida Kuenzer (1989, p. 3). Para essa autora, o princípio educativo do trabalho pressupõe a compreensão na qual "o trabalho é ponto de partida, e concebido como atividade teórico/prática, síntese entre ciência, técnica e humanismo histórico". Nesse sentido, o trabalho como princípio educativo deve proporcionar aos sujeitos envolvidos nos processos de ensino e aprendizagem a apropriação dos 
conhecimentos produzidos socialmente pela coletividade. Assim, a história do Terreiro Pai Xangô das Cachoeiras, a história das suas lideranças religiosas e o trabalho realizado para a produção do artesanato na Escola de Arte Escultural formatam essa perspectiva do princípio educativo do trabalho ao estabelecer uma relação indissociável entre esses três polos constitutivos dessa relação.

Outro autor que também defende a ideia do princípio educativo do trabalho é o professor Demerval Saviani. Este defende que só é possível compreender o caráter educativo do trabalho se o considerarmos no seu sentido ontológico, ou seja, "o ato de agir sobre a natureza transformando-a em função das necessidades humanas é o que conhecemos com o nome de trabalho" (2007, p. 3). O trabalho com o barro e a madeira realizado pelo Terreiro, no contexto das práticas de ensino e aprendizagem realizadas no âmbito da Escola de Arte Escultural, tem esse caráter. Assume esse mesmo sentido. Os registros já apresentados sobre os aspectos da representatividade do líder religioso explicitam esse sentido do trabalho.

No Terreiro, o modo de produção comunitária coletiva das relações sociais materiais, simbólicas, espirituais e os processos educativos são inerentes a existência do Terreiro. Tal experiência encontra assento na formulação de Saviani (2007, p. 3-4), sobre o processo de produção da própria vida pelos homens e como esse processo se confunde com seu próprio processo de educação/transformação/mudança de si mesmo.

Os homens apropriavam-se coletivamente dos meios de produção da existência e nesse processo educavam-se e educavam as novas gerações. Prevalecia, aí, o modo de produção comunal, também chamado de "comunismo primitivo". Não havia a divisão em classes. Tudo era feito em comum. Na unidade aglutinadora da tribo dava-se a apropriação coletiva da terra, constituindo a propriedade tribal na qual os homens produziam sua existência em comum e se educavam nesse mesmo processo. Nessas condições, a educação identificava-se com a vida. A expressão "educação é vida", e não preparação para a vida, reivindicada muitos séculos mais tarde, já na nossa época, era, nessas origens remotas, verdade prática (SAVIANI, 2007, p. 3 -4).

É no sentido do que nos diz Saviani (2007) nesse texto, quando se refere aos sentidos da produção coletiva, tribal, comunitária, comunal, que observamos como o trabalho e a educação estão entrelaçados no fazer cotidiano da casa religiosa, principalmente, através das práticas do líder religioso enquanto mestre artesão. Apresentaremos a seção abaixo alguns elementos encontrados na pesquisa que bem caracterizam esse ambiente coletivo quando descrevermos o histórico da Escola de Arte Escultural e a organização do trabalho de 
ISSN: 2594-4827

produção do artesanato.

\section{A ESCOLA DE ARTE ESCULTURAL E A EDUCAÇÃO PARA O TRABALHO}

Tratamos anteriormente do papel do líder religioso enquanto mestre artesão e do modo de vida no Terreiro e na Escola de Arte Escultural. Percebemos que a escola é um ambiente coletivo-comunitário no qual a totalidade do patrimônio cultural material e imaterial produzido é apropriado, também, coletivamente. Postura encontrada nos trabalhos explanados por Kuenzer (1989) e Saviani (2007), discutindo o princípio educativo.

Tratamos aqui da história da Escola de Arte Escultural e dos processos educativos que nela são realizados a fim de apresentar mais elementos que caracterizam uma forma de EPT presente no Terreiro. A partir de então, podemos descrever a escola na sua postura de formadora de trabalhadores.

O Terreiro recebeu apoio do Poder Executivo municipal e de uma empresa de engenharia que estava prestando serviço ao município para construir o espaço, posteriormente, denominado de Escola de Arte Escultural. Isso aconteceu no ano de 2003. As atividades relacionadas à produção do artesanato, que eram realizadas debaixo de árvores no quintal do Terreiro, passaram a ocupar o novo espaço escolar recém construído. Cabe frisar que o apoio recebido pelo Terreiro se deu em função do prestígio e notoriedade que goza o Babalorixá José Geraldo como mestre artesão.

Esse espaço escolar passou a ser o local por excelência onde os mestres educadores (nesse momento o Ogan Elson Alves também desempenhava a função de mestre ceramista) passaram a se reunir com crianças, jovens e adultos, filhos e filhas da casa e também da comunidade do entorno para realizar o trabalho educativo/formativo da produção de artesanato. Martins (2010) descreve esse contexto da seguinte maneira:

Gerar [Geraldo] não é reconhecido apenas por sua arte. A cidade o respeita como líder religioso. Além do mais, ele realiza importante trabalho social voltado para jovens carentes. Em 2003, teve condições de fundar com a ajuda da prefeitura e de empresa local, uma escola de arte, no mesmo lugar onde mora e onde dirige, como pai de santo, o terreiro de candomblé. $\mathrm{O}$ espaço, rodeado de árvores - sua casa, os lugares de culto, a escola e a oficina -, situa-se próximo ao Rio Grande, afluente do São Francisco. O poder das águas e das energias da mata compõem uma paisagem propícia à vivencia do sagrado. O encontro dos dois rios é motivo de entusiasmo para os artistas locais e para os moradores em geral. [...] O apoio dado pela Ação 
Social da firma Injec e pela Prefeitura foi fundamental na construção e manutenção da escola de Arte Escultural. Apesar de seu firme objetivo de ensinar aos meninos da redondeza, Gerar não dispunha de lugar adequado e não contava com a ajuda de ninguém (MARTINS, 2010, p. 67 e 78).

Esse enfoque da autora no papel do líder religioso, na construção da Escola e nas práticas de ensino e aprendizagem para crianças e jovens carentes, caracteriza a relação do Terreiro com a Educação, informando a novidade que se caracteriza com a extensão do processo educativo para englobar a comunidade circunvizinha ao Terreiro. O que evidencia que esse processo educativo possibilitou formação e profissionalização de artesãos e ceramistas para além dos muros da casa religiosa.

Mesmo tendo recebido apoio institucional do Poder Executivo local para a construção da Escola de Arte Escultural, esse espaço escolar que se constituiu como referência de formação para a cidadania e para o mundo do trabalho de crianças, jovens e adultos não tem nenhuma vinculação institucional/formal com nenhuma rede de Ensino.

Saviani (1994) ao tratar do sentido e da função da educação na sociedade atual diz que a educação se confunde com a escola e chama a atenção para o papel dominante que a escola assume no pensamento social. Também chama a atenção para o fato que, ao mesmo tempo que escola passa a ser compreendida como sendo o lugar por excelência para a realização da educação, a educação ocorre em outros espaços e tempos que não se confundem com os espaços e tempos da escola.

Que a forma escolar emerge como forma dominante de educação na sociedade atual. Isto a tal ponto que a forma escolar passa a ser confundida com a educação propriamente dita. Assim, hoje, quando pensamos em educação, automaticamente pensamos em escola. E por isso que quando se levantam bandeiras em prol da educação, o que está em causa é o problema escolar. Se a educação escolar é a forma dominante na sociedade atual, compreende-se por que as demais formas de educação, ainda que subsistam na sociedade moderna, passam para um plano secundário, se subordinam à escola e são aferidas a partir da escola. [...] nesse sentido que é possível compreender a educação a partir da escola e não o contrário. As formas não escolares de educação têm que ser compreendidas a partir da escola, que é a forma desenvolvida de educação. Este é o fenômeno que observamos hoje em dia, a tal ponto que, quando falamos em escola, não é necessário adjetivar; todos entendem do que se está falando. Mas quando se quer falar em educação que não seja a da escola, temos que fazer a referência sempre pela via negativa: educação não escolar, educação não formal, informal. $\mathrm{O}$ critério para entender as demais é a forma escolar. (SAVIANI, 1994, p.6).

Nesse aspecto, a construção do espaço escolar dentro do terreiro também segue essa lógica que faz com que a escola assuma esse papel dominante de educação na sociedade atual. 
Por isso, a Escola de Arte Escultural também pode ser considerada, do ponto de vista do aspecto formal da lei, um espaço que garante um processo educacional e tecnológico nos moldes do que prevê a Lei $\mathrm{n}^{\circ}$ 9.394/1996. Para tanto, basta observamos o capítulo III, da Educação Profissional e Tecnológica, no artigo 42. Neste, fica estabelecido uma condição especial de matrícula, sem vincular matrícula à escolaridade:

Art. 42. As instituições de educação profissional e tecnológica, além dos seus cursos regulares, oferecerão cursos especiais, abertos à comunidade, condicionada a matrícula à capacidade de aproveitamento e não necessariamente ao nível de escolaridade (Brasil, 1996).

Independentemente desse possível enquadramento formal legal, as práticas educativas realizadas no Terreiro a partir da Escola de Arte Escultural também se assentam numa outra perspectiva que o próprio Saviani (1994) apresenta, quando diz que a escola formal é um dentre os vários espaços/formas de educação presente hoje em dia na sociedade.

E muito comum hoje afirmar-se que a escola é uma das formas de educação, uma entre muitas e, entre estas, não é a principal. Educa-se através de múltiplas organizações, não apenas através da escola. Educa-se, por exemplo, através dos sindicatos, dos partidos, das associações dos mais diversos tipos, através dos clubes, do esporte, dos clubes de mães. Educa-se através do trabalho, através da convivialidade do relacionamento informal das pessoas entre si. Daí se considera que a escola é uma entre essas muitas formas de educar e não é a que tem maior peso. [...] Com efeito, no interior desse processo foram mantidas, obviamente com novas configurações, formas importantes de educação à margem da escola, especialmente aquelas diretamente ligadas às atividades produtivas. Assim, a formação profissional foi sendo organizada no interior do próprio aparelho produtivo, com destaque para as fábricas, brotando daí organizações que, refletindo a tendência dominante, assumiram a forma de escolas de tipo especial, as escolas profissionalizantes, como um sistema paralelo e independente da escola propriamente dita. Esse fenômeno pode melhor ser compreendido à luz da divisão entre trabalho manual e trabalho intelectual (SAVIANI, 1994, p. 7 e 10).

A Escola de Arte Escultural se configura como esse espaço destituído de "formalidade" descrito por Saviani (19994), que aproveita a capacidade das crianças, jovens e adultos, filhos e filhas da casa e também da comunidade do entorno, para inseri-los no processo de ensino e aprendizagem tecnológico e profissionalizante inerente a produção do artesanato.

Até aqui, neste tópico, o estudo privilegiou o processo produtivo do artesanato realizado pelo Terreiro a partir do novo espaço educativo - a Escola de Arte Escultural - onde a educação corresponde às necessidades do trabalho manual e intelectual, nos marcos da EPT. 
Nesse mesmo sentido, passamos a apresentar a estrutura da Escola, tendo em vista a visita in loco. A área total é de 300 metros quadrados, sendo 10 metros de largura por 30 metros de comprimento. $\mathrm{Na}$ área interna existe uma mesa enorme de concreto medindo 1 metro e meio de largura por 10 metros de cumprimento, arrodeada por bancadas de madeira.

$\mathrm{Na}$ parede do fundo tem prateleiras feitas de alvenaria, no lado direito, sentido leste, estão os banheiros e uma sala que mede 3 metros de largura por 7 metros de cumprimento onde são armazenados os objetos produzidos. Uns prontos e outros restando apenas os retoques finais. A escola está dentro da área do Terreiro e o quintal do Terreiro também é utilizado para algumas atividades da escola como as desenvolvidas com argila em função do tamanho do objeto a ser construído. O que se aplica também ao trabalho com madeira em função das ferramentas e materiais que são utilizados.

\section{Figura 4: Placa de inauguração da construção da Escola de Arte Escultural (foto 04) e Escola de Arte Escultural (foto 05).}

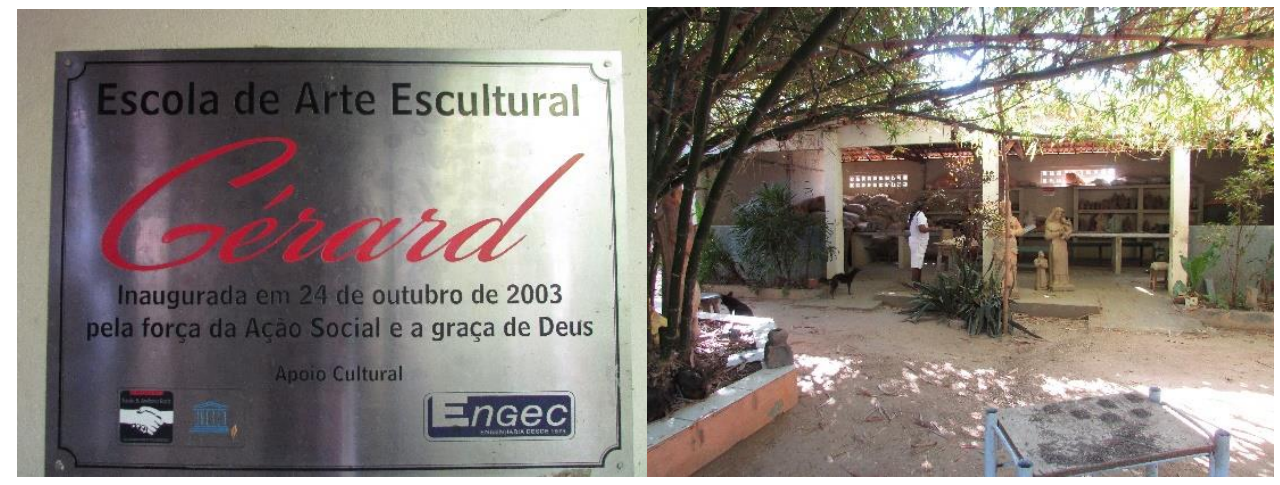

Arquivo pessoal: Registro realizado em visita à comunidade

A visita in loco, possibilitou perceber não só aspectos estruturais, arquitetônicos e de infraestrutura da Escola de Arte Escultural, mas também o caráter pedagógico, tecnológico e profissional objetivado em toda essa estrutura bem como nas peças e artefatos armazenados nas dependências do espaço escolar. Sobre a dimensão pedagógica expressa no ambiente do Terreiro em sua totalidade, a professora Terezinha Oliveira Santos (2019, p.14), autora de um outro texto, que registra a experiência educativa da casa religiosa, cujo título é o 'Fazer do Artesão', fala não só sobre José Geraldo Machado da Silva, como mestre/educador, e sobre o ambiente comunitário acolhedor que oferta conforto espiritual, mas também sobre os elementos ligados à aprendizagem da arte oleira, o que ela considera característicos de um 
espaço pedagógico.

As portas do terreiro "Xangô das Cachoeiras" estão abertas para aqueles que para ali se dirigem em busca de cura para seus males espirituais, mesmo que depois muitos afirmem que nunca pisaram ali. No terreiro funciona um ateliê, aberto para crianças e jovens em situação de risco. O terreiro do axé é um espaço pedagógico. Com aprendizagem da arte oleira muitos jovens carentes têm se desviado das rotas epistemicidas e homicidas representadas pelo mundo do crime (SANTOS, 2019, p.14).

O próprio título do texto da autora - Fazer do Artesão - informa um sentido de EPT presente no Terreiro. Santos (2019) também faz uma captura do fazer pedagógico do Terreiro à luz de uma aprendizagem tecnológica e profissionalizante ao afirmar que há "aprendizagem da arte oleira" a partir do funcionamento de um "ateliê aberto para crianças e jovens em situação de risco".

No Terreiro Pai Xangô das Cachoeiras, denominado por Santos (2019) como "espaço pedagógico" identifica-se a existência de uma metodologia própria. Essa metodologia está centrada nos usos do barro e da madeira utilizados para a produção dos artefatos, objetos e peças de artesanatos. A definição dessa metodologia fica explícita nos relatos de alunos aprendizes da Escola de Arte Escultural e do próprio líder religioso do Terreiro, conforme constam no filme Reconvexo: Santos de Cerâmica de Barra, Artesãos da Cultura Baiana. Essa produção cinematográfica foi produzida e co-produzida pela FQ Cinema e Vídeo e Movioca Content House, em 2013. Os outros parceiros foram a Universidade Federal da Bahia e o Governo do Estado.

Os relatos, apresentados no filme, mostram uma metodologia voltada para o trabalho, principalmente, com o barro, e pode ser caracterizada e definida a partir dos seguintes passos e orientações/instruções: a) Os alunos são orientados a realizar todo o trabalho manualmente sem o auxílio de nenhum equipamento; b) O barro precisa ser molhado na "maloca", local que corresponde a um tanque de alvenaria; c) Depois o barro é amassado para amolecer e ficar uniforme, ponto ideal para a feitura dos rolos, formato ideal para ser guardado em sacos plásticos; d) Com o barro totalmente preparado e no ponto para o uso, utiliza-se como instrumentos, pedaços de cabaça para feitura das peças; e) Formatando o objeto que se planejou, o final do processo de feitura das peças é a pintura e a queima no forno a lenha por um tempo de mais ou menos 8 horas.

Esses passos e orientações/instruções identificados nos relatos dos alunos conformam uma organização metodológica das práticas pedagógicas de ensino e de aprendizagem na 
ISSN: 2594-4827

Escola de Arte Escultural do Terreiro que também pode ser observada no relato do Babalorixá sobre o trabalho com o barro. Tal relato está presente no filme Reconvexo (2013).

Então nós temos aí esse trabalho com barro, onde primeiro é feita a retirada dos alagadiços que ficam entre os Rios Grande e São Francisco, para ser colocado numa maloca (tanque) onde é molhado depois é amassado para que seja feito os rolos e guardado em um saco plástico para depois ser utilizado para fazer as peças. E é pegado aquele pedaço de barro que foi embalada no saco de plástico, tira o saco, molha a parte de baixo e depois deixa um pouco no sol, depois vou fazendo os contornos da peça que se pretende; o acabamento é feito com pedaço de uma cabaça; esse pedaço de cabaça é denominado de "coité". E depois leva ao sol para endurecer mais um pouco e depois a gente vai fazendo acabamento, os contornos da peça que você pretende criar: se gera um vaso, uma panela; essa peça já desenhada é colocada no sol para endurecer. Se essa peça tiver uma tampa, uma parte superior, repete o mesmo processo da anterior com essa outra parte e leva o sol para endurecer. Essas peças prontas são feitas os acabamentos finais utilizando facas velhas, panos velhos que são molhados com a própria água que é utilizada em todo o processo para fazer o acabamento. Chegado esse ponto as peças são colocadas no sol para secar $e$ depois de seco, vão fazer a pintura com dois tipos de materiais, a Tabatinga e Tauá. A tabatinga é feita de uma rocha, uma pedra branca que é retirada das margens do Rio São Francisco; já o tauá é uma areia do Rio Grande onde faz um processo de retirada da areia, dos grãos de areia, para que a tinta que está colada nesses grãos seja separada para ser usada na pintura das peças da casa. Depois desse processo, onde as peças já foram levadas ao forno, a tonalidade da tinta utilizada é a rosada. A Tabatinga permanece na tonalidade branca; $O$ tauá que antes era da cor amarela fica avermelhado. Tirado do forno é feito o teste em cada peça para saber se não tem problema, defeito ou alguma avaria para poder disponibilizar para comercialização do produto na peça.

A descrição dos passos e orientações/instruções, ou seja, a metodologia que se segue para o trabalho com barro para a produção do artesanato, constante nos relatos dos estudantes e do próprio Babalorixá, acentua ainda o valor educativo das práticas de produção do artesanato com barro e madeira à luz do que consideramos EPT. A respeito do valor formativo e tecnológico das práticas pedagógicas realizadas pelo Terreiro, Saviani (2007) apresenta um bom exemplo, ao descrever de que modo a atividade prática pode contribuir para explicar a relação entre ciência e produção tecnológica a partir da transformação de materiais como madeira e metal.

Um exemplo de como a atividade prática, manual, pode contribuir para explicitar a relação entre ciência e produção é a transformação da madeira e do metal pelo trabalho humano (cf. Pistrak, 1981, p. 55- 56). O trabalho com a madeira e o metal tem imenso valor educativo, pois apresenta possibilidades amplas de transformação. Envolve não apenas a produção da maioria dos objetos que compõem o processo produtivo moderno, mas 
também a produção de instrumentos com os quais esses objetos são produzidos. No trabalho prático com madeira e metal, aplicando os fundamentos de diversificadas técnicas de produção, pode-se compreender como a ciência e seus princípios são aplicados ao processo produtivo, podese perceber como as leis da física e da química operam para vencer a resistência dos materiais e gerar novos produtos. Faz-se, assim, a articulação da prática com o conhecimento teórico, inserindo-o no trabalho concreto realizado no processo produtivo (SAVIANI, 2007, p. 9-10).

Com os relatos extraídos do filme Reconvexo (2013), bem como o próprio exemplo apresentado por Saviani (2007), fica evidente o princípio educativo do trabalho como orientador do fazer educativo do Terreiro, orientado para uma forma de EPT que envolve e também articula outras práticas como as religiosas, as festivas e as comunitárias da casa de candomblé.

Num outro registro a respeito do Terreiro, Martins (2010), chama a atenção para esse aspecto do trabalho educativo/formativo presente no terreiro quando afirma que o Babalorixá, tem como um dos aspectos mais importantes do trabalho que desenvolve a transmissão a outros do seu dom e da sua técnica.

Há um aspecto das atividades de Gerar muito importante: a dimensão de seu trabalho social com a arte. Trata-se de não perder um legado, de transmitir aos outros o seu dom e a sua técnica. Existe, também, outro objetivo: o de tirar crianças e jovens de um meio que os desencaminha, afasta-os do estudo e lança-os na droga. Muitas vezes o artista obteve ótimos resultados (2010, p.76).

Martins (2010), assim como Santos (2019), captou mais uma dimensão singular da EPT presente no Terreiro no momento em que afirma que o líder religioso tem como premissa central a dimensão da transmissão da sua técnica. Esse registro de Martins (2010) é outro indicativo que nos ajudou na compreensão e identificação do caráter religioso, educativo, tecnológico e profissional das atividades com artesanato realizadas no Terreiro.

Essa relação indissociável entre o trabalho, a educação e a religiosidade que existe no Terreiro pode ser compreendida, também, em paralelo à seguinte compreensão de Moura, Garcia e Ramos (2007, p. 45), sobre a relação indissociável entre trabalho, ciência, tecnologia e cultura.

Compreender a relação indissociável entre trabalho, ciência, tecnologia e cultura significa compreender o trabalho como princípio educativo, o que não significa "aprender fazendo", nem é sinônimo de formar para o exercício do trabalho. Considerar o trabalho como princípio educativo equivale dizer que o ser humano é produtor de sua realidade e, por isso, se apropria dela e pode transformá-la. Equivale dizer, ainda, que nós somos sujeitos de nossa 
história e de nossa realidade. Em síntese, o trabalho é a primeira mediação entre o homem e a realidade material e social (MOURA; GARCIA; RAMOS, 2007, p. 45).

Com base na compreensão desses autores de que há uma relação indissociável entre trabalho, ciência, educação, tecnologia, cultura e religião, este estudo, sobre o processo de ensino e aprendizagem que ocorre na Escola de Arte Escultural do Terreiro Pai Xangô das Cachoeiras, demonstra como a EPT é realizada por esse segmento de Povos e Comunidades Tradicionais. Com esse estudo também foi possível identificar e compreender como o modo de vida desses Povos e das Comunidades Tradicionais são constitutivos de epistemologias e de sentidos políticos outros, direcionando para um modo particular de fazer a Educação, o Trabalho, a Ciência, a Cultura, a Arte e a Tecnologia. Assim, cada um desses grupos expressa cosmovisão própria de civilização e de mundo.

\section{À GUISA DE CONCLUSÃO}

Com este estudo fizemos um exercício intelectual, articulando as compreensões em torno da EPT e suas possibilidades de realização em espaços não formais de educação. Trouxemos bases conceituais que dão sustentabilidade teórico-filosófica a essa perspectiva educacional em EPT, mas abrimos uma articulação com o modo de vida dos Povos das Comunidades Tradicionais, tendo como segmento escolhido para a realização do estudo um Terreiro de Candomblé localizado no sertão da Bahia.

Com esse exercício, ensaiamos um processo de racialização da proposta de EPT, sendo o Terreiro o principal fundamento para tal racialização. Sem deixar, no entanto, de lançar mão das formulações teóricas e epistemológicas que dão conta de uma construção da educação, da escola, do ensino, da aprendizagem, da cultura, das artes.

Apresentamos os resultados do estudo, mostrando a história do Terreiro Pai Xangô das Cachoeiras, da principal liderança religiosa, do artesanato produzido no ambiente do Terreiro, da construção de um espaço escolar próprio para o desenvolvimento do trabalho educativo realizado com o barro e a madeira. Mostramos o envolvimento das pessoas que convivem na casa religiosa, sejam filhos e filhas de santo, sejam da comunidade do entorno.

Finalizamos mencionando que não há dúvidas de que a EPT ocorre em espaços não formais de educação de modo organizada e estruturada, garantindo habilidades e competências no mesmo formato preconizado pela educação formal, a qual é realizada nas 
instituições públicas e privadas integrantes dos sistemas públicos e privado de ensino.

Não há dúvidas do potencial educativo, tecnológico, profissionalizante que existe nos modos de vida dos diversos segmentos dos Povos e Comunidades Tradicionais.

\section{REFERÊNCIAS}

BRASIL. Lei $\mathrm{n}^{\circ}$ 9.394, de 20 de dezembro de 1996. Estabelece as diretrizes e bases da educação nacional. Disponível em: http://www.planalto.gov.br/ccivil_03/leis/19394.htm; Acesso em: 10 de novembro de 2020.

BRASIL. Lei $\mathbf{n}^{\mathbf{0}} \mathbf{1 1 . 6 4 5}$, de 10 março de 2008. Altera a lei no 9.394, de 20 de dezembro de 1996, modificada pela lei no 10.639, de 9 de janeiro de 2003, que estabelece as diretrizes e bases da educação nacional, para incluir no currículo oficial da rede de ensino a obrigatoriedade da temática "história e cultura afro-brasileira e indígena".Disponível em: http://www.planalto.gov.br/ccivil 03/ ato2007-2010/2008/lei/111645.htm;Acesso em: 16 de novembro de 2020.

BRASIL. Lei $\mathbf{n}^{\mathbf{0}}$ 12.288, de 20 de julho de 2010. Estatuto da Igualdade Racial. Disponível em: http://www.planalto.gov.br/ccivil 03/ ato2007-2010/2010/lei/112288.htm; Acesso em: 11 de novembro de 2020.

BRASIL. Lei $\mathbf{n}^{\circ}$ 13.005, de 25 de junho de 2014. Aprova o Plano Nacional de Educação PNE e dá outras providências. Disponível em: http://www.planalto.gov.br/ccivil_03/_ato2011-2014/2014/lei/113005.htm; Acesso em: 10 de novembro de 2020.

BRASIL. Decreto $\mathbf{n}^{\mathbf{0}}$ 6.040, de 7 de fevereiro de 2007. Institui a Política Nacional de Desenvolvimento Sustentável dos Povos e Comunidades Tradicionais. Disponível em: http://www.planalto.gov.br/ccivil_03/_ato2007-2010/2007/decreto/d6040.htm; Acesso em 11 de novembro de 2020.

BRASIL. Decreto $\mathbf{N}^{\mathbf{0}} \mathbf{4 . 8 8 7}$, de 20 de novembro de 2003. Regulamenta o procedimento para identificação, reconhecimento, delimitação, demarcação e titulação das terras ocupadas por remanescentes das comunidades dos quilombos de que trata o art. 68 do Ato das Disposições Constitucionais Transitórias. Disponível em: <http://www.planalto.gov.br/ccivil_03/decreto/ 2003/d4887.htm>. Acesso em: 13 de novembro de 2020.

COSTA, Renata Silva da. Candomblé e educação: outros olhares epistemológicos. In: XII Congresso Nacional de Educação (EDUCERE), 2015, Curitiba. Disponível em: https://educere.bruc.com.br/arquivo/pdf2015/20480 8767.pdf; Acesso em: 15 de julho de 2020.

DORE, Rosemary. Afinal, o que significa o trabalho como princípio educativo em Gramsci? Cadernos do CEDES. Campinas, v. 34, n. 94, p. 297-316, set./dez. 2014. Disponível em: https://www.scielo.br/pdf/ccedes/v34n94/0101-3262-ccedes-34-94-0297.pdf; Acesso em 10 de outubro de 2020. 
FEDERAÇÃO DE UMBANDA E CANDOMBLÉ DOS CULTOS AFRO-BRASILEIRO. Diploma de Umbanda. Feira de Santana, Bahia, 8 de janeiro de 1988.

DELLA FONTE, Sandra Soares. Formação no e para o trabalho. Educação Profissional e Tecnológica em Revista. v. 2, $\mathrm{n}^{\circ}$ 2. Vitória: IFES, 2018, p. 6-19. Disponível em: <http://ojs2.ifes.edu.br/index.php/ept/article/view/1221/709> Acesso em 13 de outubro de 2020

GARCIA, Adilso de C.; DORSA, Arlinda Canteiro.; OLIVEIRA, Maria Augusta C. A educação profissional no Brasil: origem e trajetória. Revista Vozes dos Vales, p.1-18, 2018. Disponível em: 〈www.ufvjm.edu.br/vozes〉. Acesso em: 13 de outubro de 2020.

HARGREAVES, Patricia. Os orixás mais populares do Brasil. Super Interessante. Disponível em: <https://super.abril.com.br/sociedade/os-orixas-mais-populares-do-brasil/>. Acesso em: 07/08/2020.

KUENZER, Acacia Zeneida. O Trabalho como Princípio Educativo. Cadernos de Pesquisa, São Paulo: Fundação Carlos Chagas, n. 68, p. 21-28, 1989. Disponível em: <http://publicacoes.fcc.org.br/ojs/index.php/cp/article/view/1118/1123>. Acesso em 16 de outubro de 2020.

LIMA, Ricardo Gomes. Louça de perfeição: a cerâmica baiana do município de Barra. Rio de Janeiro: Funarte, 1996, 20 p.

MARTINS, Flavia; LUZ, Rogerio. Santeiros da Bahia: arte popular e devoção. Recife: Caleidoscópio, 2010.

MOREIRA, Antonio Flavio, CANDAU, Vera Maria (org.). Multiculturalismo: diferenças culturais e práticas pedagógicas. 2. ed. - Petrópolis, RJ: Vozes, 2008.

MOURA, Dante Henrique.; GARCIA, Sandra Regina de O.; RAMOS, Marise Nogueira. Educação Profissional Técnica de Nível Médio Integrada ao Ensino Médio. Documento Base. Ministério da Educação - Secretaria de Educação Profissional e Tecnológica: Brasília, dezembro de 2007.

OLIVEIRA, Amurabi; ALMIRANTE, Kleverton A. de. Aprendendo com o Axé: processos educativos no terreiro e o que as crianças pensam sobre ele e a escola. ILHA - v. 16, n. 1, p. 139-174, jan./jul. 2014. Disponível em: <https://periodicos.ufsc.br/index.php /ilha/article/view/2175-8034.2014v16n1p138>. Acesso em: 16 de julho de 2020.

PRESIDÊNCIA DA REPÚBLICA. Secretaria de Políticas de Promoção da Igualdade Racial. Plano Nacional de Desenvolvimento Sustentável dos Povos e Comunidades Tradicionais de Matriz Africana. 1 ${ }^{\mathrm{a}}$ edição. Brasília, janeiro de 2013.

RECONVEXO. Santos de Cerâmica de Barra: artesãos da cultura baiana. Documentário, 26 min. 2013.

SANTOS, Terezinha Oliveira. A “agência dos objetos" na arte santeira de José Geraldo Machado da Silva, "Mestre Gerard", em Barra-BA. Disponível em 
<https://www.academia.edu>. Acesso em: 17 de agosto de 2020.

SAVIANI, Dermeval. Trabalho e educação: fundamentos ontológicos e históricos. Revista Brasileira de Educação v. 12 n. 34 jan./abr. 2007. Disponível em: scielo.br/pdf/rbedu/v12n34/a12v1234.pdf>. Acesso em: 12 de outubro de 2020.

SAVIANI, Dermeval. O trabalho como princípio educativo frente às novas tecnologias. In: FERRETI, C. et al. (org.) Novas tecnologias, trabalho e educação. Petrópolis /RJ : Vozes, 1994. 